\title{
PHENOLIC ACID PROFILING IN THE LEAVES OF TABERNAEMONTANA HEYNEANA WALL. AN ENDEMIC PLANT OF THE WESTERN GHATS USING ULTRA-HIGH PERFORMANCE LIQUID CHROMATOGRAPHY COUPLED WITH QUADRUPOLE-TIME-OF-FLIGHT
}

\author{
MANASA DJ, CHANDRASHEKAR KR* \\ Department of Applied Botany, Mangalore University, Mangalagangothri, Mangalore, Karnataka, India. \\ Email: profkrchandrashekar@gmail.com
}

Received: 16 June 2019, Revised and Accepted: 16 July 2019

\section{ABSTRACT}

Objectives: The study was conducted to identify the phenolic compounds and other possible bioactive compounds present in the leaf extracts of Tabernaemontana heyneana Wall.

Methods: Phenolic acid profiling was carried out using ultra-high-performance liquid chromatography coupled with quadrupole-time-of-flight (QTOF). An internal standard syringic acid was used for quantitation of phenolic acids and naringenin for quantitation of flavonoids.

Results: The leaf extracts analysis revealed the presence of 17 compounds consisting of 14 phenolic compounds and three terpenes. Among 17 compounds, eight were the major compounds, namely, coniferyaldehyde, resveratrol, sinapic alcohol, protocatechuic acid, 4-hydroxybenzaldehyde, chlorogenic acid, rutin, and protocatechuic aldehyde. This forms the first report on the identification of these pharmaceutically important compounds in T. heyneana.

Conclusion: These findings offer clear evidence and scientific support for further research on the leaf extract of T. heyneana plant for its therapeutic purpose.

Keywords: Tabernaemontana heyneana Wall, Apocynaceae, Phenolic acids, Terpenes, UHPLC.

(c) 2019 The Authors. Published by Innovare Academic Sciences Pvt Ltd. This is an open access article under the CC BY license (http://creativecommons. org/licenses/by/4. 0/) DOI: http://dx.doi.org/10.22159/ajpcr.2019.v12i9.34581

\section{INTRODUCTION}

Plant products have been regarded as a major part of traditional medicine on which about $80 \%$ of the people are dependent for their primary health care since long herbal medicines are used as remedies for different ailments. Nowadays, there is an increasing demand for plant products in drug development since they are effective, less toxic with no side effects. Plant secondary metabolites include phenolic compounds, alkaloids, tannins, saponins, carbohydrates, glycosides, flavonoids, and steroids. Out of these, phenolic compounds have been considered as good therapeutic agents possessing various biological activities. Development of an effective tool for chemical profiling of plant and estimation of chemical constituents is essential. Chromatographic techniques are efficient and economical ways to determine the bioactive principles in herbal drug formulation [1].

Apocynaceae, commonly known as dogbanes, is a family of shrubs, small trees which are rich in alkaloids and glycosides, especially in seeds and latex. Some species are valuable sources of medicine, insecticides, fibers, and rubber [2]. The family includes 4555 species, distributed in 415 genera [3]. The genus Tabernaemontana is included under this family that consists of shrubs or small trees. Tabernaemontana heyneana Wall. is a shrub that is distributed in the Western Ghats region of Karnataka, India. It is known for its traditional uses which possess curative properties against venereal diseases, gonorrhea, respiratory problems, nervous disorders, diabetes, chronic bronchitis, rheumatism, cardiotonic ailments, and snakebite [4]. Sukumaran and Raj [5] demonstrated that the flower juice (mixed along with coconut oil) has the therapeutic effect against burning sensation of eyes and improved vision.

Several bioactive compounds were previously identified in the roots, leaves, and flowers of T. heyneana [6]. The presence of alkaloids in Apocynaceae has been well-studied [7]. Sathishkumar et al. [8] identified the presence of flavonoids such as quercetin and rutin in leaves of $T$. heyneana. Not much work has been carried out on the identification of phenolic compounds of this plant.

In the present work, the profiling of phenolic acids present in T. heyneana was carried out with the help of advanced UHPLC techniques combined with QTOF and mass spectrometry (MS).

\section{METHODS}

Plant material

The leaves of $T$. heyneana were collected from the natural forests of Dakshina Kannada, $\left(12.8158^{\circ} \mathrm{N}\right.$ and $\left.74.9241^{\circ} \mathrm{E}\right)$ Karnataka, India. The collected samples were authenticated and voucher specimen [MU/AB/DJM-01] was deposited in the herbarium collections of the Department of Applied Botany, Mangalore University. The samples were shade dried, ground into a fine powder using a domestic grinder and stored at $4^{\circ} \mathrm{C}$ until further use.

\section{Preparation of extract}

Powdered leaf sample $(20 \mathrm{~g})$ was subjected to Soxhlet extraction with three different organic solvents (chloroform, methanol, and dichloromethane $-300 \mathrm{ml}$ ) for $36 \mathrm{~h} .20 \mathrm{~g}$ of powdered leaf sample was mixed with $300 \mathrm{ml}$ of water, kept in boiling water bath $\left(70^{\circ} \mathrm{C}\right)$ for $36 \mathrm{~h}$ to get an aqueous extract. The obtained solution was filtered with Whatman filter paper No. 1 to obtain the filtrate. The filtrate was evaporated to dryness in a flash evaporator and the residue was stored in a refrigerator.

Phenolic acid analysis

Preparation of standard

The external standards used for the experiment are obtained from Sigma-Aldrich and are listed in Table 1. Standard stock solutions were prepared in methanol at a concentration of $1.0 \mathrm{mg} / \mathrm{ml}$ and stored in a refrigerator at $-20^{\circ} \mathrm{C}$ until use. The standards were filtered $(0.45 \mu \mathrm{m}$ 
Table 1: External standard mixture

\begin{tabular}{|c|c|c|c|c|c|c|}
\hline S. No. & Reference standard & RT [min] & Exact mass & $\mathrm{m} / \mathrm{z}$ positive $(+\mathrm{H})$ & $\mathrm{m} / \mathrm{z}$ negative $(-\mathrm{H})$ & Conc. $[\mu \mathrm{g} / \mathrm{ml}]$ \\
\hline 1 & CUDA (internal standard) & 15.53 & 340.273 & 341.28 & 339.265 & 0.1 \\
\hline 2 & Umbelliferone & 4.08 & 162.032 & 163.039 & 161.024 & 1 \\
\hline 3 & Rutin & 5.12 & 610.153 & 611.161 & 609.146 & 1 \\
\hline 4 & Naringin & 6.26 & 580.179 & 581.187 & 579.172 & 1 \\
\hline 5 & Naringenin & 8.43 & 272.069 & 273.076 & 271.061 & 1 \\
\hline 6 & Chrysin & 12.08 & 254.058 & 255.065 & 253.051 & 1 \\
\hline 7 & Daidzin & 4.3 & 416.111 & 417.118 & 415.104 & 1 \\
\hline 9 & 18-b-Glycyrrhetinic acid & 19.55 & 470.34 & 471.347 & 469.332 & 1 \\
\hline 10 & Glycitein & 7.69 & 284.069 & 285.076 & 283.061 & 1 \\
\hline 11 & Glycitin & 4.63 & 446.121 & 447.129 & 445.114 & 1 \\
\hline 12 & Genistin & 5.36 & 432.106 & 433.113 & 431.098 & 1 \\
\hline 13 & Betulinic acid & 21.55 negative & 456.36 & 457.368 & 455.353 & 1 \\
\hline 14 & Genistein & 8.62 & 270.053 & 271.06 & 269.046 & 1 \\
\hline 15 & 6-Hydroxyflavone & 10.86 & 238.063 & 239.07 & 237.056 & 1 \\
\hline
\end{tabular}

CUDA: (12-[(cyclohexylamino) carbonyl] amino]-dodecanoic acid), RT: Retention time, Conc: Concentration

filters) and diluted whenever necessary with methanol. Further, these solutions were used for method development.

\section{Preparation of sample for analysis}

The extract $(10 \mu \mathrm{g})$ was suspended in methanol $(50 \mu \mathrm{l})$ containing $100 \mu \mathrm{g} / \mathrm{ml}$ of an internal standard CUDA. The samples were sonicated (5 min) and centrifuged (3 min at 14,000 rpm), subsequently transferred to amber vials and closed immediately.

\section{Instrumentation}

Agilent 1290 Infinity UHPLC coupled with Agilent 6530 Accurate Mass QTOF with the following specifications was used for the analysis.

- Waters Acquity UHPLC BEH $\mathrm{C}_{18} 1.7 \mu \mathrm{m}, 2.1 \times 100 \mathrm{~mm}$ column for sample analysis.

- The column temperature was $65^{\circ} \mathrm{C}$.

- A binary solvent system was used A: Water with $0.1 \%$ acetic acid; B: $100 \%$ acetonitrile without a modifier.

- Flow rate $0.5 \mathrm{ml} / \mathrm{min}$.

- An injection volume of $1 \mu \mathrm{l}$ was used in both the polarity modes.

- A 15 min gradient was established with an elution starting from $0-1 \min 0 \% \mathrm{~B}$

$1-6 \min 30 \% \mathrm{~B}$

$7-9.5 \min 80 \% \mathrm{~B}$

9.5-10 $\min 99 \% \mathrm{~B}$

11 min hold

12 min back to $0 \%$.

- All solutions were filtered through a cellulose membrane with $0.45 \mu \mathrm{m}$ aperture before injection.

- For mass spectroscopic analysis, phenolic compounds were run both in negative ionization mode (Electron spray ionization - $\mathrm{ESI}^{-}$) and positive ionization mode $\left(\mathrm{ESI}^{+}\right)$.

- The autosampler was maintained at $4^{\circ} \mathrm{C}$.

- The phenolic acids were detected over the range of mass to charge ratio (m/z) 100-1700.

- An internal standard syringic acid was used for quantitation of phenolic acids, whereas $( \pm)$ naringenin was used for the quantitation of flavonoids.

- Sample aliquots were pooled for MSMS analysis from like treatments to ease analyte profiling.

- The injections were repeated 17 times to check the stability of the method for every $2 \mathrm{~h}$

- Tentative identification of phenolic compounds was done based on accurate mass and retention times.

\section{Data analysis}

Data acquisition on metabolic profiles was subjected to further processing adopting the liquid chromatography QTOF MS Mass Hunter Qualitative (for alignment and molecular feature extraction) and
MassHunter Professional (statistical analysis) programs. All the graphs were plotted in Microsoft Excel, and the structure of the identified compounds was drawn using ChemSketch software.

\section{RESULTS AND DISCUSSION}

UHPLC detection in both positive $[\mathrm{M}+\mathrm{H}]^{+}$and negative $[\mathrm{M}-\mathrm{H}]$ ionization modes revealed the presence of 17 compounds of which 14 are phenolic acids and three are terpenes. The phenolic acids included four flavonoids, two stilbenes, five cinnamic derivates, and four benzoic acid derivatives. Data concerning the identification of the compounds are shown in Tables 2 and 3 where the RT, m/z, molecular weight, molecular formula, and the class of metabolite for which they belong to, in positive $[\mathrm{M}+\mathrm{H}]^{+}$and negative $[\mathrm{M}-\mathrm{H}]^{-}$ion mode of all the detected compounds are reported. The reported structures of these phytocompounds are shown in Table 4.

Five phenolic acids and one terpene were identified in positive mode $[\mathrm{M}+\mathrm{H}]^{+}$(Table 2), namely, 6-methoxyluteolin $[\mathrm{m} / \mathrm{z}$ 316.26], coniferyaldehyde $[\mathrm{m} / \mathrm{z}$ 178.18], sinapic alcohol $[\mathrm{m} / \mathrm{z}$ 210.229], resveratrol [m/z 228.247], polydatin [m/z 390.384], and cauloside C,respectively.Tenphenolicacidsandtwoterpenesweredetectedinnegative mode (Table 3), namely, hesperidin [m/z 610.57], rutin [m/z 610.521], spiraeoside[m/z464.379], syringaldehyde [m/z182.17], protocatechuic acid $[\mathrm{m} / \mathrm{z}$ 154.12], 4-hydroxybenzaldehyde $[\mathrm{m} / \mathrm{z} \quad 122.123]$, protocatechuic aldehyde [m/z 138.122], chlorogenic acid [m/z 354.31], esculetin [m/z 178.14], ferulic acid [194.18], asiatic acid [m/z 488.699], and medicagenic acid [m/z 502.692].

\section{Identification of phenolic acids} Flavonoids

Phenolic acids are a group of secondary metabolites existing as a soluble ester or glucoside forms in plants. These compounds are mainly generated through phenylpropanoid pathway and are broadly classified into derivatives of the hydroxycinnamic acid such as ferulic acid and caffeic acid; derivatives of the hydroxybenzoic acid such as gallic acid and vanillic acid [9]. Similarly, flavonoids, as the main class of phenolic compounds, demonstrate a wide range of biochemical and pharmacological effect [10]. Sathishkumar and Baskar [11] revealed the presence of flavonoids which agrees with the results of the present investigation.

Altogether, four flavonoids were detected in both the ionization modes with a maximum of three in negative mode $[\mathrm{M}-\mathrm{H}]^{-}$. It has been well studied that the negative ionization mode $[\mathrm{M}-\mathrm{H}]^{-}$gives better resolution for flavonoid, probably because of the loss of protons from the acidic hydroxyl groups and their enhanced ionization. However, the positive ionization $[\mathrm{M}+\mathrm{H}]^{+}$mode may reveal more structural and fragmentation information about the flavonoid. Plenty of flavonoids synthesized in plants is linked to sugars (glycosides), despite being 
Table 2: Phenolic acids in positive mode

\begin{tabular}{|c|c|c|c|c|c|c|c|c|}
\hline S. No. & Annotations & Identifier & Class of metabolite & RT (Library) & RT (Sample) & {$[\mathrm{M}+\mathrm{H}]^{+}$} & $\begin{array}{l}\text { Molecular } \\
\text { weight }\end{array}$ & $\begin{array}{l}\text { Molecular } \\
\text { formula }\end{array}$ \\
\hline 1 & 6-Methoxy luteolin & $4.53-317.06$ & Flavones & 9.329 & 4.531 & 317.06 & 316.26 & $\mathrm{C}_{16} \mathrm{H}_{12} \mathrm{O}_{7}$ \\
\hline 2 & Coniferyaldehyde & $4.11-179.07$ & $\begin{array}{l}\text { Cinnamic acid derivative } \\
\text { (Hydroxycinnamaldehyde) }\end{array}$ & 6.081 & 4.107 & 179.07 & 178.18 & $\mathrm{C}_{10}^{16} \mathrm{H}_{10}^{12} \mathrm{O}_{3}$ \\
\hline 3 & Sinapic alcohol & $3.86-211.10$ & $\begin{array}{l}\text { Cinnamic acid derivative } \\
\text { (Phenylpropionates) }\end{array}$ & 6.474 & 3.864 & 211.098 & 210.229 & $\mathrm{C}_{11} \mathrm{H}_{14} \mathrm{O}_{4}$ \\
\hline 4 & Resveratrol & $3.87-229.11$ & Stilbene & 6.95 & 3.868 & 229.11 & 228.247 & $\mathrm{C}_{14} \mathrm{H}_{12} \mathrm{O}_{3}$ \\
\hline 5 & Polydatin & $3.82-391.16$ & Stilbene & 5.149 & 3.868 & 391.16 & 390.38 & $\mathrm{C}_{20} \mathrm{H}_{22} \mathrm{O}_{8}$ \\
\hline 6 & Cauloside C & $10.99-767.53$ & Triterpene & 19.241 & 10.991 & 767.53 & 766.959 & $\mathrm{C}_{41}^{20} \mathrm{H}_{66}^{22} \mathrm{O}_{13}^{8}$ \\
\hline
\end{tabular}

$[\mathrm{M}+\mathrm{H}]^{+}$: Samples analyzed by UHPLC-ESI-MS in positive ion mode, RT: Retention time

Table 3: Phenolic acids in negative mode

\begin{tabular}{|c|c|c|c|c|c|c|c|c|}
\hline S. No. & Annotations & Identifier & Class of metabolite & $\begin{array}{l}\text { RT } \\
\text { (Library) }\end{array}$ & $\begin{array}{l}\text { RT } \\
\text { (sample) }\end{array}$ & {$[\mathbf{M}-\mathbf{H}]^{-}$} & $\begin{array}{l}\text { Molecular } \\
\text { weight }\end{array}$ & $\begin{array}{l}\text { Molecular } \\
\text { formula }\end{array}$ \\
\hline 1 & Hesperidin & $6.29-609.18$ & Flavanone & 7.886 & 6.288 & 609.181 & 610.57 & $\mathrm{C}_{28} \mathrm{H}_{34} \mathrm{O}_{15}$ \\
\hline 2 & Rutin & $4.10-609.15$ & Flavone & 5.201 & 4.1 & 609.147 & 610.521 & $\mathrm{C}_{27}^{28} \mathrm{H}_{30}^{34} \mathrm{O}_{16}^{15}$ \\
\hline 3 & Spiraeoside & $4.22-463.09$ & Flavonol & 6.747 & 4.222 & 463.089 & 464.379 & $\mathrm{C}_{21}^{27} \mathrm{H}_{20} \mathrm{O}_{12}$ \\
\hline 4 & Syringaldehyde & $3.99-181.05$ & $\begin{array}{l}\text { Benzoic } \\
\text { derivative-Hydroxybenzaldehyde }\end{array}$ & 4.779 & 3.987 & 181.05 & 182.17 & $\mathrm{C}_{9} \mathrm{H}_{10} \mathrm{O}_{4}$ \\
\hline 5 & Protocatechuic acid & $1.20-153.02$ & $\begin{array}{l}\text { Benzoic } \\
\text { derivative-Hydroxybenzoic acids }\end{array}$ & 1.57 & 1.204 & 153.02 & 154.12 & $\mathrm{C}_{7} \mathrm{H}_{6} \mathrm{O}_{4}$ \\
\hline 6 & 4-Hydroxybenzaldehyde & $2.82-121.03$ & $\begin{array}{l}\text { Benzoic } \\
\text { derivative-Hydroxybenzaldehyde }\end{array}$ & 2.871 & 2.823 & 121.03 & 122.123 & $\mathrm{C}_{7} \mathrm{H}_{6} \mathrm{O}_{2}$ \\
\hline 7 & Protocatechuic aldehyde & $1.82-137.02$ & Benzoic derivative- Catechols & 2.101 & 1.816 & 137.02 & 138.122 & $\mathrm{C}_{7} \mathrm{H}_{6} \mathrm{O}_{3}$ \\
\hline 8 & Chlorogenic acid & $1.31-353.09$ & $\begin{array}{l}\text { Cinnamic acid } \\
\text { derivative-Cinnamates }\end{array}$ & 2.375 & 1.31 & 353.089 & 354.31 & $\mathrm{C}_{16} \mathrm{H}_{18} \mathrm{O}_{9}$ \\
\hline 9 & Esculetin & $2.52-177.02$ & $\begin{array}{l}\text { Cinnamic acid } \\
\text { derivative-Hydroxycoumarins }\end{array}$ & 2.752 & 2.5217 & 177.021 & 178.14 & $\mathrm{C}_{9} \mathrm{H}_{6} \mathrm{O}_{4}$ \\
\hline 10 & Ferulic acid & $4.04-193.05$ & $\begin{array}{l}\text { Cinnamic acid } \\
\text { derivative-Hydroxycinnamic acids }\end{array}$ & 4.92 & 4.041 & 193.051 & 194.18 & $\mathrm{C}_{10} \mathrm{H}_{10} \mathrm{O}_{4}$ \\
\hline 11 & Asiatic acid & $8.32-487.34$ & Terpenes-pentacyclic triterpenes & 18.737 & 8.782 & 487.34 & 488.699 & $\mathrm{C}_{30} \mathrm{H}_{48} \mathrm{O}_{5}$ \\
\hline 12 & Medicagenic acid & $7.85-501.32$ & Terpenes-Triterpenes & 20.21 & 7.848 & 501.369 & 502.692 & $\mathrm{C}_{30}^{30} \mathrm{H}_{46}^{48} \mathrm{O}_{6}^{3}$ \\
\hline
\end{tabular}

$[\mathrm{M}-\mathrm{H}]^{-}$: Samples analyzed by UHPLC-ESI-MS in negative ion mode, RT: Retention time

found as aglycones. During the analysis, three flavonoids were detected as $[\mathrm{M}-\mathrm{H}]^{-}$ions such as flavones (Rutin), flavanone (Hesperidin), and flavonol (Spiraeoside) whereas 6-methoxyluteolin (flavone) as $[\mathrm{M}+\mathrm{H}]^{+}$ion which is in accordance with Sanchez-Rabaneda et al. [12] who could detect flavonoids such as rutin, 6-methoxy luteolin, and quercetin in $[\mathrm{ESI}]^{-}$mode. Previous studies reported the presence of rutin in T. heyneana [8] and Tabernaemontana catharinensis [13]. El-Gayed et al. [14] also witnessed the identification of hesperidin in Tabernaemontana coronaria. Therapeutic effects of this plant might be attributed to the presence of these flavonoids. Among the identified flavonoids rutin was found to be the major flavonoid in the leaf extracts of T. heyneana (Fig. 1). The presence of 6-methoxyluteolin and hesperidin in $T$. heyneana is being reported for the first time.

\section{Benzoic acid derivatives}

Benzoic acid derivatives are simple phenolic acids ubiquitously present in plants which usually occur in conjugated or esterified forms. The simpler type of benzoic acid derivatives identified in the leaf extracts of $T$. heyneana includes syringaldehyde ( $\mathrm{m} / \mathrm{z}$ 182.05), protocatechuic acid (m/z 154.12), 4-hydroxybenzaldehyde (m/z 122.123), and protocatechuic aldehyde (m/z 138.122). The identification of these compounds was facilitated by the analysis of fragmentation pathways of $[\mathrm{M}-\mathrm{H}]^{-} /[\mathrm{M}+\mathrm{H}]^{+}$ions in the negative ion $[\mathrm{M}-\mathrm{H}]^{-}$modes. Some of the benzoic acid derivatives were detected as negative ions in the fruits of Melicoccus bijugatus Jacq. [15] which is in accordance with the result of the present study. Sun et al. [16] detected the benzoic acid derivatives in $[\mathrm{M}+\mathrm{H}]^{+}$mode which is contrary to the present report. Protocatechuic acid is widely distributed and present in most of the edible plants which are used in folk medicine.

\section{Cinnamic acid derivatives}

Cinnamic acid derivatives are widespread in occurrence usually exist in a bound form such as esters. In the current study, five cinnamic acid derivatives were identified which includes coniferyaldehyde $[\mathrm{M}+\mathrm{H}]^{+}$at $\mathrm{m} / \mathrm{z}$ 178.18, sinapic alcohol $[\mathrm{M}+\mathrm{H}]^{+}$ at $\mathrm{m} / \mathrm{z}$ 210.229, chlorogenic acid $[\mathrm{M}-\mathrm{H}]^{-}$at $\mathrm{m} / \mathrm{z}$ 354.31, esculetin $[\mathrm{M}-\mathrm{H}]^{-}$at $\mathrm{m} / \mathrm{z}$ 178.14, and ferulic acid $[\mathrm{M}-\mathrm{H}]^{-}$at $\mathrm{m} / \mathrm{z}$ 194.18. In the present study, cinnamic acid derivatives were detected in both the modes of ionization which is in agreement with the previously published data [17]. Chlorogenic acid was earlier reported in Tabernaemontana catharinensis by Piana et al. [13] and ferulic acid in Tabernaemontana coronaria by El-Gayed et al. [14]. Sinapyl alcohol was documented earlier in cell suspension cultures of Tabernaemontana divaricata by Dagnino et al. [18]. Earlier reports are available on the identification of coniferaldehyde and esculetin in other medicinal plants [19]. This is the first study reporting these cinnamic acid derivatives in the leaf extracts of T. heyneana which may be associated with medicinal uses exhibited by this plant.

\section{Stilbenes}

Stilbenes such as resveratrol $[\mathrm{M}+\mathrm{H}]^{+}$at $\mathrm{m} / \mathrm{z} \quad 228.247$ and polydatin $[\mathrm{M}+\mathrm{H}]^{+}$at $\mathrm{m} / \mathrm{z} 390.38$ were detected in the leaf extracts of T. heyneana in the present study. Stilbenes are simple secondary metabolites derived from phenylpropanoid pathway having a number of implications on human health and plant defense mechanism. Kimura and Okuda [20] reported polydatin in Polygonum cuspidatum. Resveratrol exists in plants as its glycoside form, polydatin [21] which exerts a wide variety of pharmacological properties. Even stilbenes are being reported for the first time in T. heyneana. 
Table 4: Structure of the identified compounds in the leaf extracts of Tabernaemontana heyneana Wall

\section{Name of the compound \\ Flavonoid}

1. 6-Methoxy luteolin

3. Rutin

4. Spiraeoside

Benzoic derivatives

1. Protocatechuic acid

\section{4-Hydroxy benzaldehyde}

\section{Protocatechuic aldehyde}

4. Syringaldehyde

Cinnamic derivatives

1. Coniferyaldehyde

2. Sinapic alcohol<smiles>O=C(O)c1ccc(O)c(O)c1</smiles><smiles>O=Cc1ccc(O)cc1</smiles><smiles>O=Cc1ccc(O)c(O)c1</smiles><smiles>COc1cc(C=O)cc(OC)c1O</smiles><smiles>COc1cc(/C=C/C=O)ccc1O</smiles><smiles>COc1cc(/C=C/CO)cc(OC)c1O</smiles>

Table 4: (Continued)

Name of the compound

Structure of the compound

3. Chlorogenic acid

4. Esculetin

5. Ferulic acid<smiles>COc1cc(/C=C/C(=O)O)ccc1O</smiles>

Stilbenes

1. Polydatin

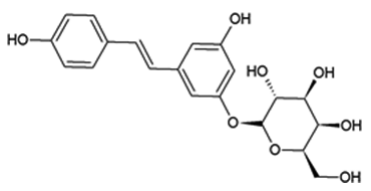

2. Resveratrol

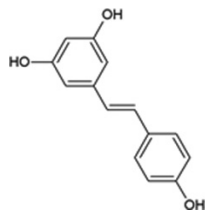

Terpenes

1. Cauloside

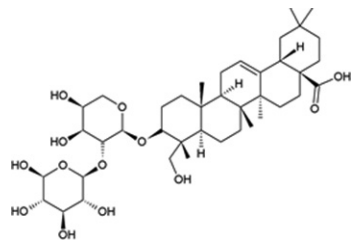

2. Asiatic acid

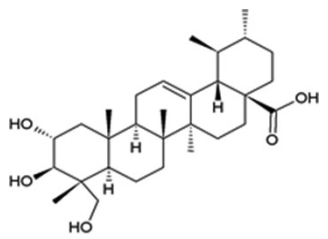

3. Medicagenic acid

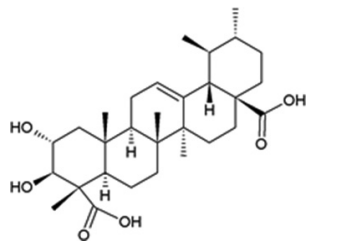

\section{Identification of terpenes}

Terpenes are the large and diverse group of phenolic compounds built up from five-carbon isoprene units linked together in a head-to-tail arrangement which possesses a large variety of physical, chemical, and biological activities. The study revealed the presence of three terpenes in T. heyneana, namely, asiatic acid [M-H] ${ }^{-}$at $\mathrm{m} / \mathrm{z}$ 488.699, cauloside $\mathrm{C}[\mathrm{M}+\mathrm{H}]^{+}$at $\mathrm{m} / \mathrm{z}$ 766.959, and medicagenic acid $[\mathrm{M}-\mathrm{H}]^{-}$ at $\mathrm{m} / \mathrm{z}$ 502.692. This is the pioneering report of these terpenes in $T$. heyneana. Rastogi and Dhar [22] reported asiatic acid, cauloside C in Centella asiatica.

Effect of solvents on the extraction of phenolic acids

Results of this work demonstrated a remarkable variability in the amounts of phenolic compounds in different solvents (Figs. 1 and 2). The high content of coniferyaldehyde, resveratrol, 


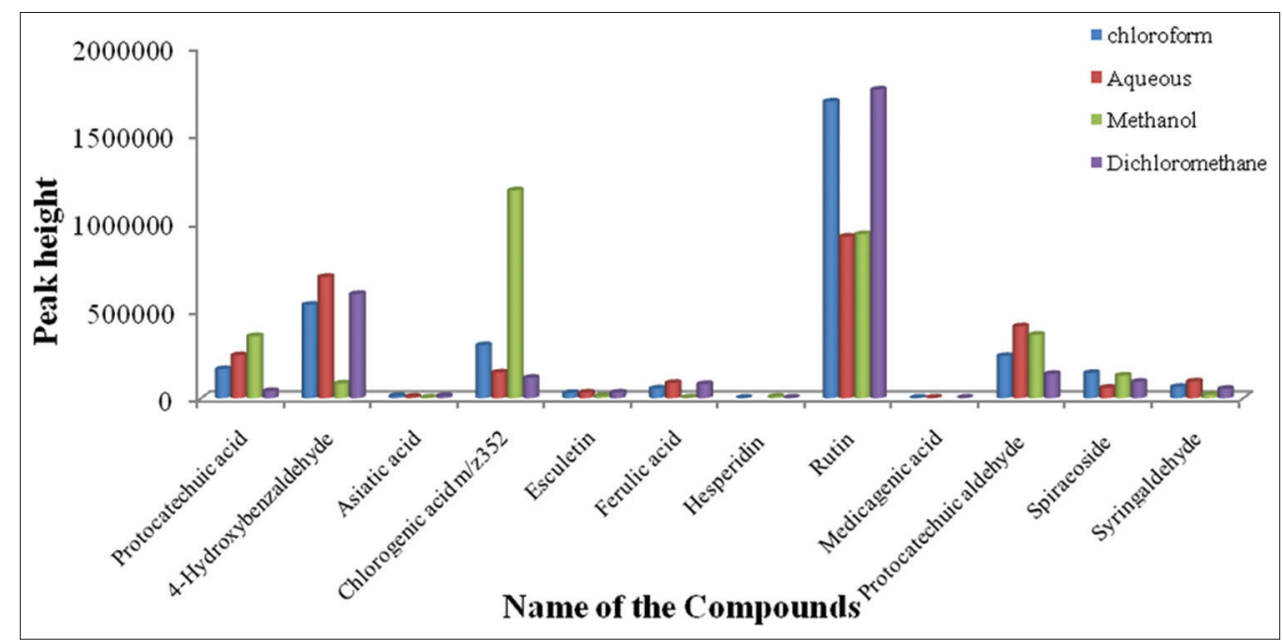

Fig. 1: Phenolic acids in different leaf extracts of Tabernaemontana heyneana (negative mode)

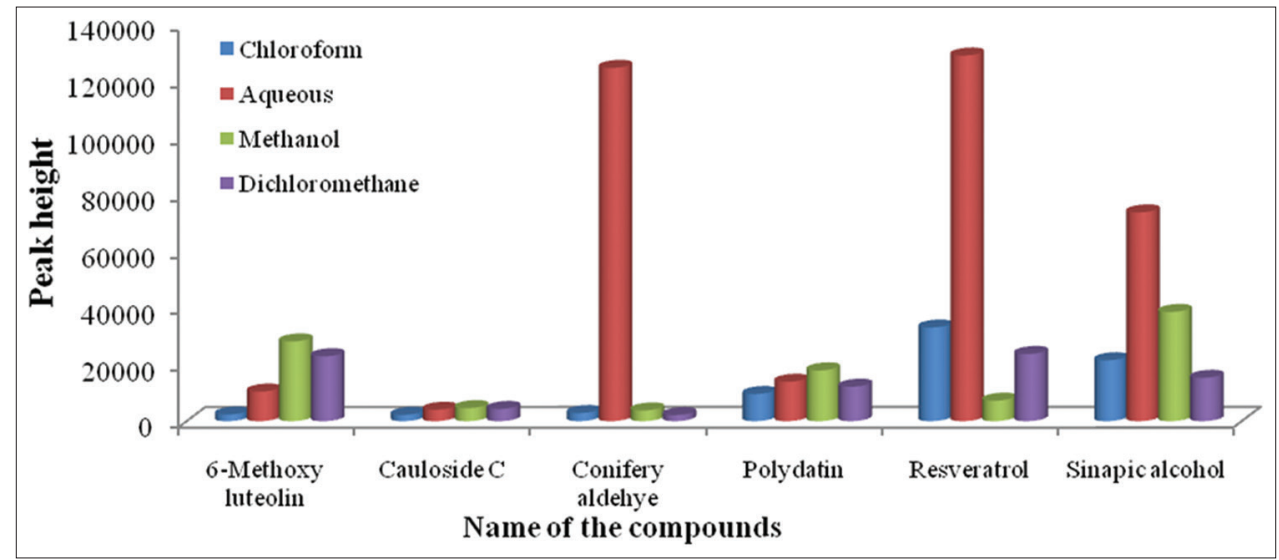

Fig. 2: Phenolic acids in different leaf extracts of Tabernaemontana heyneana (Positive mode)

sinapic alcohol, 4-hydroxybenzaldehyde, ferulic acid, syringaldehyde, and protocatechuic aldehyde was obtained from the aqueous extract. 6-methoxyluteolin, cauloside $\mathrm{C}$, polydatin, protocatechuic acid, and chlorogenic acid were found significantly in higher quantity in methanol extract. Our findings are in agreement with the previous investigation by Ertas et al. [23] wherein abundant phenolic acids were found in methanol extract. In the present study, water and methanol were proved to be the most efficient solvents for extraction of phenolic compounds compared to chloroform and dichloromethane indicating the presence of bioactive compounds which are polar in nature. In the context of these observations, it should be noted that the phenolic compounds are often associated with other biomolecules (polysaccharides, proteins, terpenes, chlorophyll, and inorganic compounds) and a solvent suitable for the extraction of particular classes of compound must be used based on the structural features and related level of aqueous solubility of a particular target molecule [24] and polarity index of the solvent. Rutin is the most abundant compound found in nonpolar solvents such as chloroform and dichloromethane (Fig. 1). Chloroform and dichloromethane gave the lowest recovery of phenolic compounds because of their lower efficiency of solvation since these are proton acceptors while methanol and water are proton donors. It was observed that a diverse group of phenolic compounds was extracted from methanol in Bucida bucera $\mathrm{L}$. and Phoradendron Californicum [25] which is in tune with the present study. In contrast, water and polar solvents seemed to be less effective in extracting phenolics in Beijing propolis extracts [26].

Among the identified phenolic acids cauloside $\mathrm{C}$, asiatic acid, esculetin, hesperidin, and medicagenic acid were found to be present in lower amounts. The leaf extracts of T. heyneana showed higher contents of coniferyaldehyde, resveratrol, sinapic alcohol, protocatechuic acid, 4-hydroxybenzaldehyde, chlorogenic acid, rutin, and protocatechuic aldehyde as observed in walnut leaves [27]

The identified phenolic compounds were responsible for numerous biological activities such as antioxidant, antimicrobial, antiinflammatory, antimutagenic, and anticarcinogenic properties [28]. They also contribute to apoptosis by arresting the cell cycle, regulating carcinogen metabolism, ontogenesis expression, inhibiting deoxyribose nucleic acid binding and cell adhesion, migration, proliferation or differentiation, and blocking signaling pathways [29,30]. All the phenolic acids identified are thought to be potent therapeutic agents. Hence, this study is the most comprehensive profiling of phenolic constituents of $T$. heyneana to date, encompassing not only flavonoids but also hydroxybenzoic and hydroxycinnamic acids. Thus, the UHPLC profiling of phenolic acids and flavonoids is likely to give a relatively realistic representation of the phytochemical contents available in T. heyneana.

\section{CONCLUSION}

Except for rutin, all the phenolic compounds detected in T. heyneana are being reported for the first time, which can serve as the source for these chemical constituents. Four flavonoids, two stilbenes, five cinnamic derivatives, four benzoic acid derivatives, and three terpenes were reported in T. heyneana. The current pioneering study suggests that these medicinally important phytocompounds are potent therapeutic agents. It sets ease for the development of numerous treatment system based on this plant extract. In the present study, water and methanol 
were proved to be the most efficient solvents for the extraction of phenolic acids and flavonoids. Further research is needed to purify the bioactive compounds responsible for its therapeutic action.

\section{ACKNOWLEDGMENT}

The senior author (Manasa DJ) is thankful to the Department of Science and Technology (DST) for awarding INSPIRE fellowship (No: DST/ INSPIRE fellowship 2012). I am also thankful to Dr. Moran Farhi for proofreading of the article and help during the experiments. I would like to show gratitude to Prof Neelima Sinha for helping me to carry out the analysis in West Coast Metabolomics Center, UC Davis, University of California.

\section{AUTHORS' CONTRIBUTIONS}

The experimental part of the research was done by the first author (Manasa DJ). The preparation of the manuscript draft and revising it critically for the intellectual content was done by Prof. Chandrashekar KR.

\section{CONFLICTS OF INTEREST}

We declare that we do not have any conflicts of interest.

\section{REFERENCES}

1. Santhosh KS, Samydurai P, Ramakrishnan R, Nagarajan N. Gas chromatography and mass spectrometry analysis of bioactive constituents of Adiantum capillus-verneris L. Int J Pharm Pharm Sci 2014;6:60-3

2. Ying T, Ping-tao L. Apocynaceae. Fl Reipubl Popularis Sin 1997;63:1-249.

3. Castro LS, Perazzo FF, Maistro EL. Genotoxicity testing of Ambelania occidentalis (Apocynaceae) leaf extract in vivo. Genet Mol Res 2009;8:440-7.

4. Duraipandiyan V, Ayyanar M, Ignacimuthu S. Antimicrobial activity of some ethnomedicinal plants used by Paliyar tribe from Tamil Nadu, India. BMC Complement Altern Med 2006;6:35

5. Sukumaran S, Raj AD. Medicinal plants of sacred groves in Kanyakumari district southern Western Ghats. Indian J Tradit Knowl 2010;9:294-9.

6. Grover RK, Srivastava S, Kulshrestha DK, Roy R. A new stereoisomer of stemmadenine alkaloid from Tabernaemontana heyneana. Magn Reson Chem 2002;40:474-6.

7. Raffauf RF, Flagler MB. Alkaloids of the Apocynaceae. Econ Bot 1960;14:37-55.

8. Sathishkumar T, Baskar R, Shanmugam S, Rajasekaran P, Sadasivam S, Manikandan V. Optimization of flavonoids extraction from the leaves of Tabernaemontana heyneana Wall. using $\mathrm{L}_{16}$ orthogonal design. Nat Sci 2008;6:10-21.

9. Huang RT, Lu YF, Inbaraj BS, Chen BH. Determination of phenolic acids and flavonoids in Rhinacanthus nasutus (L.) kurz by highperformance-liquid chromatography with photodiode-array detection and tandem mass spectrometry. J Funct Foods 2015;12:498-508.

10. Edewor-Kuponiyi TI. Spectroscopic determination of total phenolic and flavonoid contents, and antioxidant activity, of the leaves of Persea americana. Int J Pharm Pharm Sci 2013;5:598-603.

11. Sathishkumar T, Baskar R. Screening and quantification of phytochemicals in leaves and flowers in Tabernaemontana heyneana Wall. A near threatened medicinal plant. Indian J Nat Prod Resour 2014;5:237-43.

12. Sanchez-Rabaneda F, Jauregui O, Casals I, Andres-Lacueva C, Izquierdo-Pulido M, Lamuela-Raventos RM. Liquid chromatographic/ electrospray ionization tandem mass spectrometric study of the phenolic composition of cocoa (Theobroma cacao). J Mass Spectrom 2003;38:35-42.

13. Piana M, Boligon AA, Brum TF, Zadra M, Belke BV, Froeder ALF, et al. Phytochemical analysis and antioxidant capacity of Tabernaemontana catharinensis A. DC. Fruits and branches. An Acad Bras Cienc 2014;86:881-8.

14. El-Gayed SH, Kandil ZA, Abdelrahman EH. Cycloartane from Tabernaemontana coronaria (Jacq) Willd flowers with their cytotoxicity against MCF7 and HCT116 cancer cell lines. J Pharmacogn Phytochem 2015;4:35-41

15. Bystrom LM, Lewis BA, Brown DL, Rodriguez E, Obendorf RL. Characterization of phenolics by LC-UV/vis, LC-MS/MS and sugars by GC in Melicoccus bijugatus Jacq. "Montgomery" fruits. Food Chem 2008;111:1017-24.

16. Sun J, Liang F, Bin Y, Li P, Duan C. Screening non-colored phenolics in red wines using liquid chromatography/ultraviolet and mass spectrometry/mass spectrometry libraries. Molecules 2007;12:679-93.

17. Kajdzanoska M, Gjamovski V, Stefova M. HPLC-DAD-ESI-MSn identification of phenolic compounds in cultivated strawberries from Macedonia. Maced J Chem Chem Eng 2010;29:181-94.

18. Dagnino D, Schripsema J, Peltenburg A, Verpoorte R, Teunis K. Capillary gas chromatographic analysis of indole alkaloids: Investigation of the indole alkaloids present in Tabernaemontana divaricata cell suspension culture. J Nat Prod 1991;54:1558-63.

19. Zhang XY, Cai XH, Luo XD. Chemical constituents of allophylus longipes. Chin J Nat Med 2012;10:36-9.

20. Kimura Y, Okuda H. Resveratrol isolated from Polygonum cuspidatum root prevents tumor growth and metastasis to lung and tumor-induced neovascularization in Lewis lung carcinoma-bearing mice. J Nutr 2001;131:1844-9.

21. Kiselev KV. Perspectives for production and application of resveratrol. Appl Microbiol Biotechnol 2011;90:417-25.

22. Rastogi RP, Dhar ML. Chemical examination of Centella asiatica Linn. II. Brahmoside and brahminoside. Indian J Chem 1963;1:267-9.

23. Ertaş A, Boğa M, Yılmaz MA, Yeşil Y, Haşimi N, Kaya MŞ, et al. Chemical compositions by using LC-MS/MS and GC-MS and biological activities of Sedum sediforme (Jacq.) Pau. J Agric Food Chem 2014;62:4601-9.

24. Ghasemzadeh A, Jaafar HZ, Rahmat A. Effects of solvent type on phenolics and flavonoids content and antioxidant activities in two varieties of young ginger (Zingiber officinale Roscoe) extracts. J Med Plants Res 2011;5:1147-54

25. Iloki-Assanga SB, Lewis-Lujan LM, Lara-Espinoza CL, GilSalido AA, Fernandez-Angulo D, Rubio-Pino JL. Solvent effects on phytochemical constituent profiles and antioxidant activities, using four different extraction formulations for analysis of Bucida buceras L. and Phoradendron californicum. BMC Res Notes 2015;8:1-14.

26. Sun $\mathrm{C}$, Wu Z, Wang Z, Zhang H. Effect of ethanol/Water solvents on phenolic profiles and antioxidant properties of Beijing propolis extracts. Evid Based Complement Alternat Med 2015;2015:595393.

27. Nour V, Trandafir I, Cosmulescu S. HPLC determination of phenolic acids, flavonoids and juglone in walnut leaves. J Chromatogr Sci 2013;51:883-90.

28. Balasundram N, Sundram K, Samman S. Phenolic compounds in plants and agri-industrial by-products: Antioxidant activity, occurrence, and potential uses. Food Chem 2006;99:191-203.

29. Grieb SM, Theis RP, Burr D, Benardot D, Siddiqui T, Asal NR, et al. Food groups and renal cell carcinoma: Results from a case-control study. J Am Diet Assoc 2009;109:656-67.

30. Pradeepa M, Kalidas V, Geetha N. Qualitative and quantitative phytochemical analysis and bactericidal activity of Pelargonium graveolens L'her. Int J Appl Pharm 2016;8:7-11. 